\title{
Vasoactive-Ventilation-Renal Score Predicts Cardiac Care Unit Length of Stay in Patients Undergoing Re-Entry Sternotomy: A Derivation Study
}

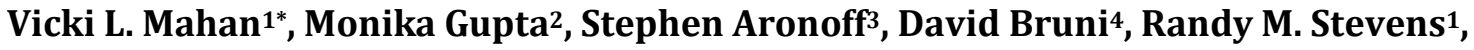 \\ Achintya Moulick ${ }^{1}$ \\ ${ }^{1}$ Division of Pediatric Cardiothoracic Surgery/Department of Surgery, St. Christopher's Hospital for Children/Drexel University \\ College of Medicine, Philadelphia, USA \\ ${ }^{2}$ Division of Critical Care/Department of Pediatrics, St. Christopher's Hospital for Children/Drexel University College of \\ Medicine, Philadelphia, USA \\ ${ }^{3}$ Division of Pediatric Infectious Disease/Department of Pediatrics, Lewis Katz School of Medicine at Temple University, \\ Philadelphia, USA \\ ${ }^{4}$ Drexel University College of Medicine, Philadelphia, USA \\ Email: *mahan_vicki@yahoo.com
}

How to cite this paper: Mahan, V.L. Gupta, M., Aronoff, S., Bruni, D., Stevens, R.M. and Moulick, A. (2018) Vasoactive-Ventilation-Renal Score Predicts Cardiac Care Unit Length of Stay in Patients Undergoing Re-Entry Sternotomy: A Derivation Study. World Journal of Cardiovascular Surgery, 8, 7-21.

https://doi.org/10.4236/wjcs.2018.81002

Received: December 19, 2017

Accepted: January 15, 2018

Published: January 18, 2018

Copyright $\odot 2018$ by authors and Scientific Research Publishing Inc. This work is licensed under the Creative Commons Attribution International License (CC BY 4.0).

http://creativecommons.org/licenses/by/4.0/

\section{c) (i) Open Access}

\begin{abstract}
Background: The vasoactive-ventilation-renal (VVR) score includes pulmonary and renal dysfunctions not previously addressed by the vasoactive inotrope score (VIS) and may be a better predictor of cardiac care unit (CCU) length of stay (LOS) in patients undergoing re-entry sternotomy (defined as no earlier than 30 days after previous sternotomy) for congenital heart disease (CHD). Methods: Patients undergoing re-entry sternotomy for CHD from August 1, 2009 to June 30, 2016 were studied retrospectively. A total of 96 patients undergoing 133 re-entry procedures were identified. VVR scores were calculated on CCU admission post-procedure (at 0 hour), 24-hour, and 48-hour after admission to the CCU. The response variable was CCU LOS. Recursive partition analysis identified variables predicting LOS. Results: 133 re-entry sternotomies in 96 patients made up the samples of the database; 11 samples were removed due to incomplete data or placement on ECMO. Of the initial 25 features, 5 were removed for near zero variance and 3 categorical features were removed for non-information. Covariance analysis did not demonstrate any significant correlation amongst the remaining features. Initial recursive tree regression using ANOVA, cross validation and conditional predictive $p$-value $(\mathrm{cp})=0.01$ produced 3 trees. The tree with lowest cross validation error was selected. The resulting 2 split trees with ventilator days less
\end{abstract}


than 20 days and VVR score at 48 hours greater than 23 identified three CCU LOS groups with mean CCU LOS of 77.6, 55.1, and 9.5 days. Conclusions: Recursive partition analysis identified ventilator days greater than 20 days and the sub-population VVR at 48 hours as predictive of CCU LOS in patients undergoing re-entry sternotomy for CHD.

\section{Keywords}

Re-Entry Sternotomy, Vasoactive-Ventilation-Renal Score, VVR Score, Recursive Partitioning Analysis, Congenital Heart Disease (CHD)

\section{Introduction}

A newer severity of injury score, the vasoactive-ventilation-renal (VVR) score [1], addresses dysfunction of the pulmonary and renal systems not previously addressed by the vasoactive inotrope score (VIS) [2]. Calculation of the score is shown in Figure 1. The stratification tool is highly predictive of outcome, is simple, and is straight forward to calculate. In the initial study of its application, 48-h VVR was a predictor of prolonged intubation, prolonged use of vasoactive infusions, chest tube drainage, and intensive care unit (ICU) and hospital length of stay (LOS) and outperformed VIS and peak postoperative lactate in a retrospective analysis of infants following congenital heart surgery [1]. Prospective validation by Miletic and colleagues in a heterogeneous population of pediatric patients undergoing cardiac surgery found the 48-h VVR score to be a predictor of outcomes and outperformed VIS [3]. Prolonged hospital LOS was predicted by the VVR at 12 hours in another prospective study by Scherer et al. of a heterogeneous population of patients undergoing congenital heart surgery [4]. Multicenter validation of the score in neonatal cardiac surgery is ongoing [5].

Improved survival of patients with congenital heart disease (CHD) after initial cardiac surgery has resulted in an increase of re-entry sternotomies, a now common procedure that is not associated with increased operative mortality but is associated with an increased risk of postoperative morbidities [6] [7] [8]. While morbidities in this population of patients have not been well defined, ICU LOS is an indicator of morbidity. Application of the VVR score in this subpopulation

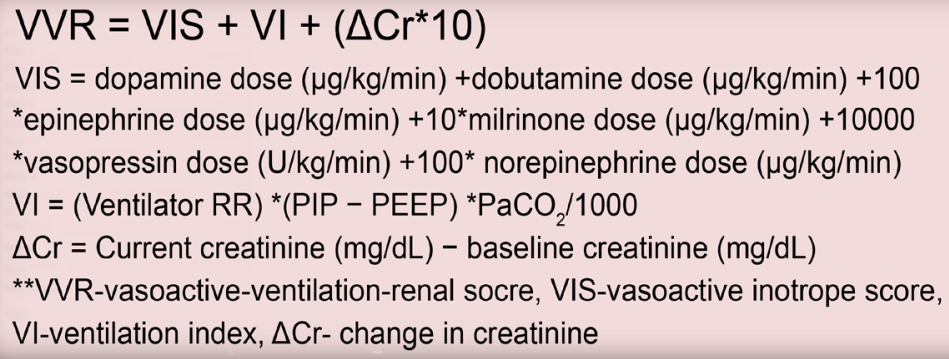

Figure 1. Calculation of VVR score. 
of patients to predict CCU LOS will further validate the use of the VVR score as a predictive stratification tool. We focused our study on this patient population and postulated that the VVR score would be predictive of cardiac care unit (CCU) LOS and result in risk stratification of this subpopulation of patients and allow us to determine which patients are at higher risk for morbidity and mortality.

\section{Patients and Methods}

\subsection{Patient Population}

The pediatric cardiac surgery database at St. Christopher's Hospital for Children in Philadelphia, Pennsylvania was queried to identify all cases undergoing re-entry sternotomy for CHD from August 1, 2009 to June 30, 2016. The Institutional Review Board within the Human Research Protection Program (HRPP) of the Office of Research at Drexel University approved the study as Exempt Category 4. Consent was waived by the Institutional Review Board. Cases that required extracorporeal membrane oxygenation (ECMO) within the first 48 hours of CCU admission were excluded from analysis as ventilator and inotrope support would be related to the use of mechanical support and not CHD severity. Cases that had incomplete data were also excluded from analysis.

\subsection{Data Collection}

Demographic, preoperative, perioperative, and postoperative variables were abstracted. Preoperative data collected included age, height and weight at the time of surgery, anatomic diagnosis, race, gender, genetic and chromosomal abnormalities, presence of non-cardiac abnormalities, need for preoperative ventilation, and preoperative serum creatinine. Perioperative data included operation performed, cardiopulmonary bypass time, aortic cross-clamp time, duration of deep hypothermic circulatory arrest, and Society of Thoracic Surgeons-European Association for Cardio-Thoracic Surgery Congenital Heart Surgery (STAT) mortality category [9]. Need for ECMO, nitric oxide, and/or delayed sternal closure were recorded. Data collected postoperatively included arterial blood gas and lactate measurements (performed simultaneously), inotrope and vasopressor support and ventilator settings including respiratory rate, fraction of inspired oxygen, peak inspiratory pressure, positive end-expiratory pressure, and mean airway pressure were recorded at the time of each arterial blood gas analysis (Table 1). Post-operative cardiac patients at our facility are usually managed using a structured protocol for inotropes and synchronized intermittent mandatory ventilation/pressure-regulated volume control and extubated at the discretion of the team in the cardiac care unit when the patient is breathing spontaneously on minimal ventilator settings for age, is able to manage secretions, has adequate gas exchange and has appropriate acid-base balance. Serum creatinine levels were obtained at baseline, on admission to the CCU, and on postoperative days 1 and 2. Bleeding requiring surgical re-exploration, volume of packed red blood cells and other blood products, and arrhythmias in the initial 48 hours were also recorded. 
Table 1. Data collected.

\begin{tabular}{|c|c|}
\hline PREOPERATIVE DATA COLLECTED & ADMISSION TO CCU (DATA COLLECTED, VVR CALCULATED) \\
\hline AGE, HEIGHT, AND WEIGHT AT TIME OF SURGERY & ARTERIAL BLOOD GASES \\
\hline ANATOMIC DIAGNOSIS & LACTATE \\
\hline GENETIC/CHROMOSOMAL ABNORMALITIES & INOTROPES \\
\hline NON-CARDIAC ABNORMALITIES & VENTILATOR SETTINGS \\
\hline PREOPERATIVE VENTILATION & SERUM CREATININE \\
\hline \multicolumn{2}{|l|}{ SERUM CREATININE } \\
\hline & $\begin{array}{l}24 \text { HOURS AFTER ADMISSION TO CCU } \\
\text { (DATA COLLECTED, VVR CALCULATED) }\end{array}$ \\
\hline PERIOPERATIVE DATA COLLECTED & ARTERIAL BLOOD GASES \\
\hline OPERATION PERFORMED & LACTATE \\
\hline STAT MORTALITY CATEGORY & INOTROPES \\
\hline CARDIOPULMONARY BYPASS TIME & VENTILATOR SETTINGS \\
\hline AORTIC CROSS CLAMP TIME & SERUM CREATININE \\
\hline \multicolumn{2}{|l|}{ DURATION OF DHCA } \\
\hline NEED FOR ECMO & $\begin{array}{l}48 \text { HOURS AFTER ADMISSION TO CCU } \\
\text { (DATA COLLECTED, VVR CALCULATED) }\end{array}$ \\
\hline NEED FOR NITRIC OXIDE & ARTERIAL BLOOD GASES \\
\hline NEED FOR DELAYED STERNAL CLOSURE & LACTATE \\
\hline \multirow[t]{2}{*}{ INJURY TO MEDIASTINAL STRUCTURES } & INOTROPES \\
\hline & VENTILATOR SETTINGS \\
\hline OTHER DATA COLLECTED & SERUM CREATININE \\
\hline \multicolumn{2}{|l|}{$\begin{array}{l}48 \text { HOURS AFTER RE-ENTRY STERNOTOMY } \\
\text { (0 HOUR BEING ADMISSION TO CCU) }\end{array}$} \\
\hline \multicolumn{2}{|l|}{ SEPSIS DURING HOSPITALIZATION } \\
\hline RENAL FAILURE DURING HOSPITALIZATION & \\
\hline
\end{tabular}

\subsection{Derivation of the Vasoactive Ventilation Renal Score}

Vasoactive inotrope score (VIS) was calculated on admission to the CCU and at 24 and 48 hours after admission to the CCU. Calculation of VIS was as follows: VIS $=$ dopamine dose $(\mathrm{mcg} / \mathrm{kg} / \mathrm{min})+$ dobutamine dose $(\mathrm{mcg} / \mathrm{kg} / \mathrm{min})+100$ * epinephrine dose $(\mathrm{mcg} / \mathrm{kg} / \mathrm{min})+10 *$ milrinone dose $(\mathrm{mcg} / \mathrm{kg} / \mathrm{min})+10,000$ * vasopressin dose $(\mathrm{U} / \mathrm{kg} / \mathrm{min})+100 *$ norepinephrine dose $(\mathrm{mcg} / \mathrm{kg} / \mathrm{min})$.

If the patient was not on inotropes at the time of the arterial blood gas measurement, VIS was zero.

Ventilation index (VI) was on admission to the CCU and at 24 and 48 hours after admission to the CCU. Calculation of VI was as follows [3]:

$\mathrm{VI}-($ Ventilator respiratory rate $) *(\mathrm{PIP}-\mathrm{PEEP}) * \mathrm{PaCO}_{2} / 1000$, where PIP is 
peak inspiratory pressure in $\mathrm{cm}_{2} \mathrm{O}$ and PEEP is positive end-expiratory pressure in $\mathrm{cm} \mathrm{H}_{2} \mathrm{O}$. VI was equal to zero if the patient was not on the ventilator at the time of the arterial blood gas measurement.

Preoperative serum creatinine was subtracted from serum creatinine on post-operative day 1 and post-operative day 2 . This was $\Delta \mathrm{Cr}$. If the serum creatinine was equal to or less than baseline, the $\Delta \mathrm{Cr}$ was recorded as zero.

VVR was calculated as follows:

$\mathrm{VVR}=\mathrm{VIS}+\mathrm{VI}+\left(\Delta \mathrm{Cr}{ }^{\star} 10\right) . \mathrm{VVR}$ scores were recorded on admission to the CCU and at 24 hours and 48 hours after admission to the CCU.

\subsection{Statistical Analyses}

Descriptive statistics were used to summarize patient demographics, diagnoses, operations performed, and outcomes. Continuous variables were described with median (interquartile range) while categorical variables were described with frequencies and percentages. Predictor variables were chosen based on assessment of their potential for identifying subgroups with different treatment effect and practical utility.

We initially tried to determine if any relationship existed between the VVR score and CCU LOS. Univariate Cox proportional hazards models were examined. Hazard ratios and their 95\% confidence intervals were estimated. Backwards selection was employed to fit multivariable Cox proportional hazards models considering all prognostic factors until demonstrating significance at the 0.05 level. These statistical methods did not predict which variables predicted CCU LOS at the 0.05 level.

An alternative statistical approach, recursive partitioning, allowed our cohorts to be split (initially into two subgroups) by identifying a variable and cut point that leads to the greatest separation between the two groups. Each subgroup was split again using the same approach and resulting in a tree-like classification of the cohort into smaller subgroups. The number of subgroups is selected by balancing the model complexity (number of subgroups/depth of the tree) against how well the model fits the data in hand. This statistical method for multivariable analysis creates a decision tree that works to classify the cases by splitting data into sub-populations based on several dichotomous independent variables. Each sub-population may then be split an indefinite number of times until the splitting process ends after a stopping criteria is reached. The tree represents the recursive partition. Each terminal node (leaf) of the tree represents a cell of the partition and has a simple model that applies in that cell only. Advantages of this statistical method include making predictions quickly; it is easy to understand what variables are important in making the prediction, if some data is missing; we may not be able to go all the way down the tree to a terminal node, but we can still make a prediction by averaging all the terminal modes in the sub-tree we do reach; the model gives a jagged response so it can work when the true regression surface is not smooth; and there are fast, reliable algorithms to learn these trees. 
Using recursive partitioning, factors were identified that influenced CCU LOS. Initial recursive tree regression using ANOVA, cross validation and conditional predictive $p$-value $(\mathrm{cp})=0.01$ was used to produce the trees. The tree with the lowest $\mathrm{cp}$ was then selected. Statistical analyses were accomplished using the rpart package. In our study, ventilator days $<20$ days defined CCU LOS and, with sub-population splitting of ventilator days $<20$ days, VVR at 48 hours $<23$ further determined CCU LOS.

\section{Results}

\subsection{Descriptive Analysis}

Ninety-six patients underwent 133 re-entry sternotomy procedures for CHD during the study period. No neonates (defined as being less than or equal to 28 days old) underwent re-entry sternotomy (Figure 2). The majority of the procedures (cases) were first re-entries (95 cases), 32 cases were second re-entries, 5 third re-entries, and 1 patient had 4 re-entries. The latter patient had a hypoplastic right lung, anomalous origin of the right pulmonary artery from the ascending aorta, and an atretic proximal right pulmonary artery. The initial surgery was placement of a pericardial tube between the aorta and the distal right pulmonary artery. This occluded and the right internal mammary artery was anastomosed to the distal right pulmonary artery in the second procedure, the right internal mammary artery was connected to the main pulmonary artery in the third procedure, and Gore-tex patch augmentation of the right internal mammary artery and right pulmonary artery reconstruction was done in the fourth procedure. The patient presented with thrombosis of the proximal neo right pulmonary artery and a right innominate artery to distal right pulmonary artery conduit was placed during the fourth re-entry sternotomy. All patients were admitted to the cardiac care unit postoperatively.

Stat categories and procedures are shown in Table 2. The most common

NUMBER OF PROCEDURES

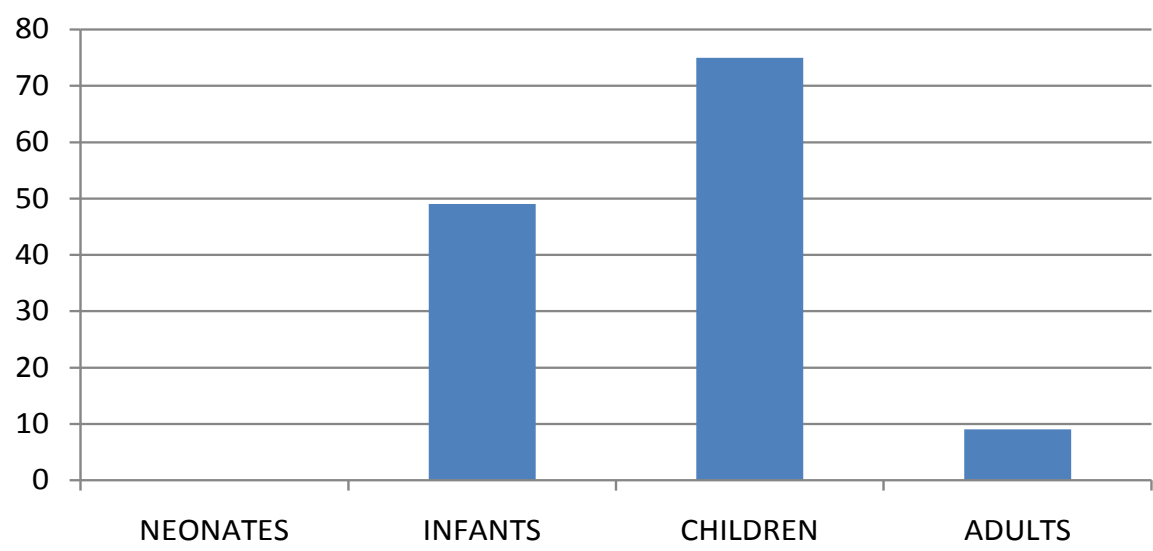

Figure 2. Neonates ( $\leq 28$ days old), infants ( $>28$ days old to $\leq 12$ months old), children ( $>12$ months old to $\leq 18$ years old), and adults ( $>18$ years old) with $\mathrm{CHD}$ undergoing re-entry sternotomy. 
Table 2. Stat categories and procedures.

\begin{tabular}{|c|c|c|}
\hline STAT CATEGORY & PROCEDURE & NUMBER \\
\hline \multirow[t]{12}{*}{ STAT 1} & VALVE REPLACEMENT, PULMONIC & 17 \\
\hline & CONDUIT REOPERATION & 10 \\
\hline & PA, RECONSTRUCTION (PLASTY), MAIN (TRUNK) & 10 \\
\hline & VSD REPAIR, PATCH & 8 \\
\hline & VALVULOPLASTY, MITRAL & 5 \\
\hline & PACEMAKER IMPLANTATION, PERMANENT & 4 \\
\hline & ASD REPAIR, PATCH & 3 \\
\hline & ANEURYSM, PULMONARY ARTERY, REPAIR & 1 \\
\hline & PAPVC REPAIR & 1 \\
\hline & ROSS PROCEDURE & 1 \\
\hline & AORTIC STENOSIS, SUBVALVAR, REPAIR & 1 \\
\hline & VALVULOPLASTY, AORTIC & 1 \\
\hline \multirow[t]{9}{*}{ STAT 2} & BIDIRECTIONAL CAVOPULMONARY ANASTOMOSIS (BIDIRECTIONAL GLENN) & 16 \\
\hline & RVOT PROCEDURE & 10 \\
\hline & TOF REPAIR, VENTRICULOTOMY, TRANSANNULAR & 5 \\
\hline & AORTIC ROOT REPLACEMENT, BIOPROSTHETIC & 2 \\
\hline & AORTIC STENOSIS, SUPRAVALVAR, REPAIR & 1 \\
\hline & VALVULOPLASTY, TRICUSPID & 1 \\
\hline & AVC (AVSD) REPAIR, COMPLETE AVSD & 1 \\
\hline & $\begin{array}{l}\text { PA, RECONSTRUCTION (PLASTY), BRANCH, PERIPHERAL } \\
\text { (WITHIN THE HILAR BIFURCATION) }\end{array}$ & 1 \\
\hline & ANEURYSM, VENTRICULAR, RIGHT, REPAIR & 1 \\
\hline \multirow[t]{6}{*}{ STAT 3} & FONTAN, TCPC, EXTERNAL CONDUIT, FENESTRATED & 14 \\
\hline & ARRHYTHMIA SURGERY ATRIAL, SURGICAL ABLATION & 2 \\
\hline & VALVE REPLACEMENT, MITRAL & 1 \\
\hline & LIGATION, PULMONARY ARTERY & 1 \\
\hline & VALVE REPLACEMENT, TRICUSPID & 1 \\
\hline & AORTIC ARCH REPAIR & 1 \\
\hline \multirow[t]{5}{*}{ STAT 4} & $\begin{array}{l}\text { SHUNT, SYSTEMIC TO PULMONARY, CENTRAL } \\
\text { (FROM AORTA OR TO MAIN PULMONARY ARTERY) }\end{array}$ & 4 \\
\hline & RASTELLI & 3 \\
\hline & $\begin{array}{c}\text { DAMUS-KAYE-STANSEL PROCEDURE (CREATION OF } \\
\text { AORTOPULMONARY ANASTOMOSIS WITH ARCH RECONSTRUCTION) }\end{array}$ & 2 \\
\hline & TAPVC REPAIR & 2 \\
\hline & SHUNT, SYSTEMIC TO PULMONARY, MODIFIED BLALOCK-TAUSSIG SHUNT & 1 \\
\hline STAT 5 & NORWOOD PROCEDURE & 1 \\
\hline
\end{tabular}


diagnoses were TOF (19.8\%) and DORV (12.5\%). The bidirectional Glenn procedure and pulmonic valve replacement were the most commonly performed procedures. The majority of the patients had a STAT mortality score of $1(47 \%)$ or $2(29 \%)$. There were no post-operative residual lesions.

Table 3 is a summary of the demographic and clinical characteristics of the patients. Sixty percent were male with a median age of 2.1 years and weight of $10.5 \mathrm{~kg}$. The majority of the patients (37\%) were African-American (Table 3). Twenty-seven per cent had chromosomal abnormalities. Cardiopulmonary bypass $(\mathrm{CPB})$ was required during 118 of the procedures (median $\mathrm{CPB}$ time 97 minutes), aortic-cross clamping in 73 (median cross-clamp time 55.5 minutes), and deep hypothermic circulatory arrest (DHCA) in 8 (median DHCA time 8 minutes). Three patients had injury of a mediastinal structure during re-entry (right ventricular outflow tract in 1, pseudoaneurysm in 1, and conduit in 1). There was no hemodynamic compromise in any of these patients and none required ECMO. Arrhythmias were seen in 36 cases-junctional rhythm in 13, bradycardia in 8 , non-sustained ventricular tachycardia in 6 , complete heart block in 6 , and supraventricular tachycardia in 3 . None of the patients required long term pacing or AICD. Five cases required ECMO support within the first 48 hours and are excluded from analysis. An additional six cases had incomplete data and are also excluded from analysis. None of the cases in the study group had delayed sternal closure and 1 required take back for bleeding. There were no deaths within 30 days of the procedure. Two deaths (2/122 cases, $1.6 \%$ ) occurred within 90 days of the surgical procedure. One death occurred at 92 days after the procedure $(1 / 122,0.8 \%)$. Total number of deaths was $3 / 122(2.5 \%)$.

In the first 48 hours after re-entry sternotomy, 97 of the 128 cases required PRBC (range of $3 \mathrm{cc} / \mathrm{kg}$ to $651 \mathrm{cc} / \mathrm{kg}$, mean $107 \mathrm{cc} / \mathrm{kg}$, median $91 \mathrm{cc} / \mathrm{kg}$ ), 101 cases required FFP (range of $3 \mathrm{cc} / \mathrm{kg}$ to $150 \mathrm{cc} / \mathrm{kg}$, mean $48.5 \mathrm{cc} / \mathrm{kg}$, median 39 $\mathrm{cc} / \mathrm{kg}$ ), 85 cases required cryoprecipitate (range of $5 \mathrm{cc} / \mathrm{kg}$ to $29 \mathrm{cc} / \mathrm{kg}$, mean 5 $\mathrm{cc} / \mathrm{kg}$, median $4 \mathrm{cc} / \mathrm{kg}$ ), 106 cases required platelets (range of $2 \mathrm{cc} / \mathrm{kg}$ to $120 \mathrm{cc} / \mathrm{kg}$, mean $26 \mathrm{cc} / \mathrm{kg}$, median $23 \mathrm{cc} / \mathrm{kg}$ ), and 6 cases required rFactorVIIa (range of 20 $\mathrm{mcg} / \mathrm{kg}$ to $100 \mathrm{mcg} / \mathrm{kg}$, mean $72 \mathrm{mcg} / \mathrm{kg}$, median $90 \mathrm{mcg} / \mathrm{kg}$ ). Twenty-three developed sepsis during the hospitalization. Median ventilator time was 16.5 hours (range 0 to 2203 hours, mean 162 hours) -42 required post-operative nitric oxide-and median CCU LOS, our primary outcome variable, was 9 days (range 3 to 366 days, mean 30 days). None of the 122 study cases received peritoneal dialysis or renal replacement therapy within 48 hours of re-entry sternotomy. Patients usually remained in the CCU until discharge and CCU LOS is, therefore, hospital LOS.

Median VVR scores, VIS, and lactate measurements with interquartile ranges are shown in Table 4 for all study time points. Median VVR and lactate measurements decreased in the initial 48-hour.

\subsection{Statistical Analysis}

Of the initial 25 features, 5 were removed for near zero variance and 3 categorical 
Table 3. Demographics data, stat categories, operative data.

\begin{tabular}{|c|c|}
\hline Characteristic & Patients $(n=96)$ \\
\hline Male, $\mathrm{n}(\%)$ & $58(60 \%)$ \\
\hline Age (yrs) at time of surgery & 2.1 yrs $(0.6-8.4)$ \\
\hline Weight $(\mathrm{kg})$ at time of surgery & $10.5 \mathrm{~kg}(6.6-24)$ \\
\hline \multicolumn{2}{|l|}{ Ethnicity, n (\%) } \\
\hline Caucasian & $31(32 \%)$ \\
\hline African American & $35(37 \%)$ \\
\hline Hispanic & $26(27 \%)$ \\
\hline Asian & $2(2 \%)$ \\
\hline Other & $2(2 \%)$ \\
\hline Genetic/chromosomal abnormalities, n (\%) TOTAL & $26(27 \%)$ \\
\hline Trisomy 21 & $7(7 \%)$ \\
\hline DiGeorge Syndrome & $6(6 \%)$ \\
\hline Other & $13(13.5 \%)$ \\
\hline \multirow[t]{2}{*}{ Noncardiac anatomic abnormalities, $\mathbf{n}(\%)$} & $11(11 \%)$ \\
\hline & Procedures $(n=133)$ \\
\hline \multicolumn{2}{|l|}{ STAT category, n (\%) } \\
\hline STAT 1 & $62(47 \%)$ \\
\hline STAT 2 & $38(29 \%)$ \\
\hline STAT 3 & $20(15 \%)$ \\
\hline STAT 4 & $12(9 \%)$ \\
\hline STAT 5 & $1(1 \%)$ \\
\hline Preoperative mechanical ventilation, $\mathrm{n}(\%)$ & $23(17 \%)$ \\
\hline Preoperative creatinine $(\mathrm{mg} / \mathrm{dL})$ & $0.3 \mathrm{mg} / \mathrm{dL}(0.25-0.46)$ \\
\hline $48-\mathrm{h}$ creatinine $(\mathrm{mg} / \mathrm{dL})$ & $0.3 \mathrm{mg} / \mathrm{dL}(0.23-0.43)$ \\
\hline Preoperative lactate (mg/dL) & $1.3 \mathrm{mg} / \mathrm{dL}(0.9-2)$ \\
\hline 48-h lactate (mg/DL) & $1 \mathrm{mg} / \mathrm{dL}(0.8-1.4)$ \\
\hline Cardiopulmonary bypass duration $(\mathrm{min})$ (15/133 procedures did not require $\mathrm{CPB}$ ) & $96 \min (77-120)$ \\
\hline \multicolumn{2}{|l|}{ Aortic cross-clamp duration (min) } \\
\hline (73/118 procedures that required CPB did not require aortic cross-clamping) & $55.5 \min (43.2-74)$ \\
\hline Deep hypothermic circulatory arrest, $\mathrm{n}(\%)$ & $8(6 \%)$ \\
\hline Deep hypothermic circulatory arrest (min) & $28 \min (10.5-38.2)$ \\
\hline ECMO, n (\%) & $5 / 133(3.8 \%)$ \\
\hline Postoperative inhaled nitric oxide use, $\mathrm{n}(\%)$ & $42 / 133(32.8 \%)$ \\
\hline Delayed sternal closure, $\mathrm{n}(\%)$ & $1 / 122(0.8 \%)$ \\
\hline \multicolumn{2}{|l|}{ Deaths } \\
\hline Less than 30 days & $0 / 122(0 \%)$ \\
\hline Less than 90 days & $2 / 122(1.6 \%)$ \\
\hline All deaths & $3 / 122(2.5 \%)$ \\
\hline
\end{tabular}


Table 4. VVR Score, VIS, and lactate on admission to CCU and at 24-hours and 48-hours Post-procedure.

\begin{tabular}{|c|c|c|}
\hline Admission to $\mathrm{CCU}$ & Median & IQR \\
\hline VVR score & 23.6 & $17.6-38.5$ \\
\hline VIS & 10 & $5-15$ \\
\hline Lactate $(\mathrm{mg} / \mathrm{dL})$ & 2.3 & $1.3-3.3$ \\
\hline \multicolumn{3}{|l|}{ 24-hr } \\
\hline VVR score & 16.7 & $9.8-27.5$ \\
\hline VIS & 10 & $10-12.5$ \\
\hline Lactate $(\mathrm{mg} / \mathrm{dL})$ & 1.3 & $1-1.9$ \\
\hline \multicolumn{3}{|l|}{$48-\mathrm{hr}$} \\
\hline VVR score & 10 & $2.5-21$ \\
\hline VIS & 8 & $0-10$ \\
\hline Lactate $(\mathrm{mg} / \mathrm{dL})$ & 1 & $0.8-1.4$ \\
\hline
\end{tabular}

features were removed for non-information. Covariance analysis did not demonstrate any significant correlation among the remaining features. VIS and lactate were not predictive of ICU LOS or duration of mechanical ventilation.

Initial recursive tree regression using ANOVA, 5 fold cross validation and conditional predictive p-value a complexity parameter $(\mathrm{cp})=0.01$ produced 4 trees. To avoid over-fitting, the tree with the lowest cross validation error was selected. Optimal splitting was based on ventilator days greater than 20 days and VVR at 48 hours greater than 23. The resulting 2 split trees identified three CCU LOS groups. Patients with ventilator duration $>20$ days had a mean (median) ICU LOS of 77.6 (44.5) days, patients with ventilator duration $<20$ days and 48-hour VVR $>2355.1$ (19) days, and patients with ventilator duration $<20$ days and 48-hour VVR < 239.5 (7) days (Figure 3).

\section{Comment}

Prolonged ICU LOS after surgery for CHD is associated with poor outcome. Evidence-based literature is limited for estimating morbidity and mortality in these patients, but severity of injury scores may predict which patients are at high risk for longer LOS. Vasoactive support has been suggested as a marker of severity of illness in these patients and severity of illness scores reflective of amount of support have been suggested. The Wernovsky score and its modifications, used as predictors of morbidity and mortality after congenital heart surgery, are associated with increased length of ventilation and prolonged ICU and hospital LOS [10] [11] [12]. Gaies et al. found that the amount of inotropic support in the first 48 hours after congenital heart surgery correlates with time to first extubation, length of CICU stay, and time to negative fluid balance whereas patient age or single-ventricle anatomy have no effect. The authors suggested that the VIS is an independent predictor of clinical outcome after cardiac surgery [2]. In adolescents undergoing surgery for CHD, maximal VIS on the 


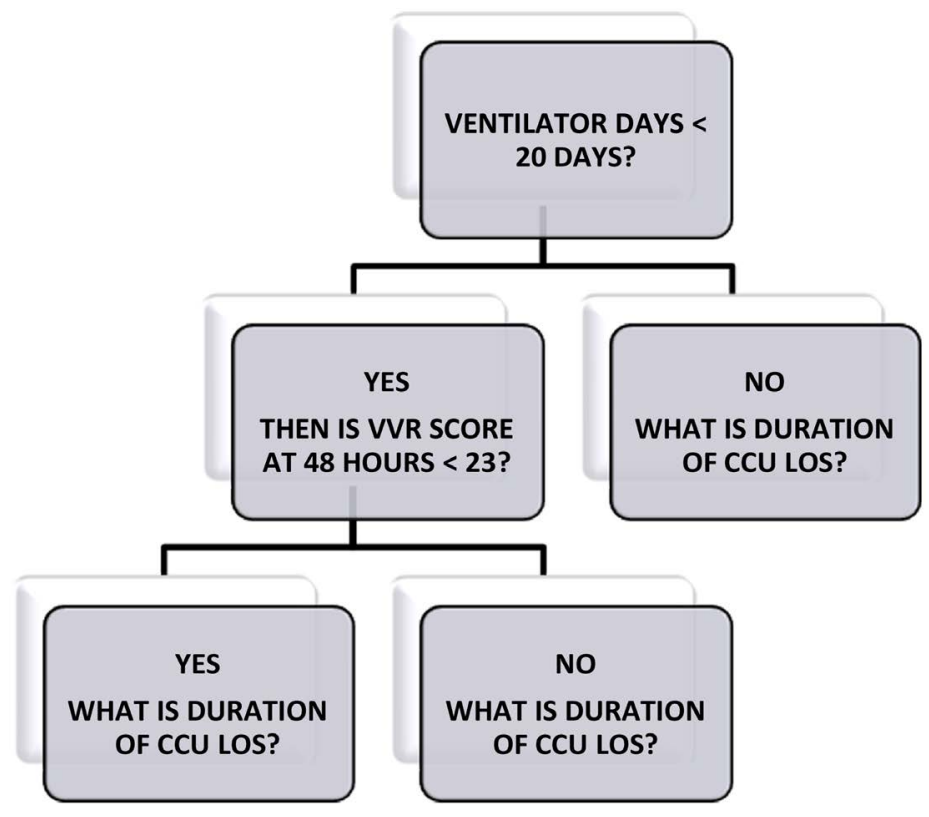

Figure 3. Nodal Splitting of Ventilation and VVR score $>23$.

second postoperative day predicted adverse outcome [13]. Also useful in pediatric patients with septic shock, Haque and colleagues showed that high inotropic score in pediatric patients with septic shock was associated with high mortality [14] and Williams et al. showed that myocardial dysfunction in fluid- and catecholamine-refractory pediatric septic shock correlated with VIS [15]. Another modification of the VIS (an extension of the VIS), the total inotrope exposure score, assesses cumulative vasoactive drug exposure and dose adjustments over time. In a single-center, retrospective study, the score predicted the poor postoperative outcomes in 167 cases. The authors suggested prospective validation across larger numbers of patients across institutions [16].

The VIS and its modifications are single system scores. A multiorgan system severity of illness index score, the VVR score, is a stratification tool that is highly predictive of outcome, builds on the VIS, is simple, and straightforward to calculate. The VVR predicts hospital LOS in children with CHD and outperforms single system scores such as VIS and peak postoperative lactate. 12-h and 48-hr VVR scores are strong predictors of prolonged hospital length of stay. VVR has been validated in children and adults undergoing surgery for CHD [1] [3] [4]. While use of 48-hour measurements avoids excessive emphasis on transient dysfunctions of cardiac/renal/respiratory systems, clinical changes in therapy based on VVR earlier (within 6 to 12 hours) would, hopefully, help to prevent further insults to the cardiac/renal/respiratory systems and result in improved outcomes. In this study of a heterogenous population of patients with CHD requiring re-entry sternotomy for palliative or surgical repair (both with and without cardiopulmonary bypass), duration of ventilation when combined with VVR was strongly predictive of ICU LOS. This further validates the use of VVR as a severity of illness score for patients undergoing surgery for CHD. 
Prolonged mechanical ventilation after surgery for CHD is also a strong predictor of clinical outcomes. Early extubation is associated with low morbidity rates and short ICU LOS in patients undergoing surgery for CHD. Most can be extubated in the operating room and most neonates undergoing surgery for complex CHD can be extubated in the first 24 hours after surgery [17] [18] [19]. Younger age, lower weight, heart failure, higher VIS, pulmonary hypertension, delayed sternal closure, greater severity of illness at post-operative admission, BUN, nitric oxide treatment, tracheobronchomalacia, peritoneal dialysis, low cardiac output, health-care associated infections, and noninfectious pulmonary complications are associated with prolonged intubation in patients undergoing surgery for CHD [20] [21] [22] [23]. Premature extubation with the need for reintubation is associated with longer ICU LOS [24]. In our patients, duration of ventilation greater than 20 days was associated with the longest CCU LOS. Patients with the combination of duration of ventilation less than 20 days and 48-hour VVR score less than 23 had the shortest CCU LOS.

In this study, we had to use a nonparametric regression model (recursive partitioning) to identify those variables predictive of CCU LOS. This method is not widely used clinically. Parametric regression methods to analyze data are designed to quantify relationships between 2 sets of variables, linear regression for continuous data, logistic regression for binary data, proportional hazard regression for censored survival data, and mixed-effect regression for longitudinal data. These methods may not lead to reproducible data descriptions when underlying assumptions are not satisfied. Recursive partitioning analysis has proved a useful alternative to the parametric regression methods, is a very easy technique to use, and can be a powerful tool to predict response in different subgroups of patients. The different methods include classification and regression trees, multivariate adaptive regression splines, forest, and survival trees [25] [26]. In our study, parametric regression methods did not identify variables predictive of CCU LOS. Statistical analysis based on recursive partitioning provided the tool of simultaneous consideration of a large number of potential predictors and identification of combinations of patient characteristics associated with good outcome. Restrictive assumptions were removed or relaxed. Duration of ventilation less than 20 days and 48-hour VVR resulted in trees identifying 3 different groups with CCU LOS relating to these variables.

\section{Limitations}

First, the analysis is based on a small sample size at a single center. Second, the study is a retrospective study. Third, not all data was available for all cases and these cases were excluded from analysis resulting in a lesser number of cases analyzed.

\section{Conclusion}

In conclusion, low morbidity and mortality resulted with re-entry sterntomy for CHD. Recursive partitioning analysis identified duration of ventilation greater 
than 20 days and 48-hour VVR greater than 23 as being predictive of CCU LOS for patients undergoing re-entry sternotomy for CHD. Further studies are needed to evaluate the role of not only VVR, but also of recursive partitioning analysis, in identifying those variables most related to CCU LOS and other morbidities and mortality in patients undergoing surgery for CHD. This single-institutional study will serve as a basis for a larger multi-institutional study which will further solidify the concept of muti-organ system severity score.

\section{Acknowledgements}

The authors wish to thank Cathy Litty, MD, Director of the Blood Bank at St. Christopher's Hospital for Children, Philadelphia, PA, for her assistance in determining blood product usage.

\section{Meeting Presentation}

7th World Congress of Pediatric Cardiology and Cardiac Surgery; Barcelona, Spain; July 16-21, 2017.

\section{References}

[1] Miletic, K.G., Spiering, T.J., Delius, R.E., Walters, H.L. and Mastropietro, C.W. (2015) Use of a Novel Vasoactive-Ventilation-Renal Score to Predict Outcomes After Paediatric Cardiac Surgery. Interactive Cardiovascular and Thoracic Surgery, 20, 289-295. https://doi.org/10.1093/icvts/ivu409

[2] Gaies, M.G., Gurney, J.G., Yen, A.H., Napoli, M.L., Gajarski R.J., Ohye R.G., Charpie, J.R. and Hirsch, J.C. (2010) Vasoactive-Inotropic Score as a Predictor of Morbidity and Mortality in Infants After Cardiopulmonary Bypass. Pediatric Critical Care Medicine, 11, 234-238. https://doi.org/10.1097/PCC.0b013e3181b806fc

[3] Miletic, K.G., Delius, R.E., Walter, H.L. and Mastropietro, C.W. (2016) Prospective Validation of a Novel Vasoactive-Ventilation-Renal Score as a Predictor of Outcomes after Pediatric Cardiac Surgery. The Annals of Thoracic Surgery, 101, 1558-1563. https://doi.org/10.1016/j.athoracsur.2015.11.006

[4] Scherer, B., Moser, E.A., Brown, J.W., Rodefeld, M.D., Turrentine, M.W. and Mastropietro, C.W. (2016) Vasoactive-Ventilation-Renal Score Reliably Predicts Hospital Length of Stay after Surgery for Congenital Heart Disease. The Journal of Thoracic and Cardiovascular Surgery, 152, 1423-1429.

https://doi.org/10.1016/j.jtcvs.2016.07.070

[5] Mastropietro, C., Cashen, K., Narayana Gowda, K.M., Piggott, K., Wilhelm, M. and Costello, J. (2016) Multicenter Validation of the Vasoactive-Ventilation-Renal Score for Neonatal Cardiac Surgery. Critical Care Medicine, 44, 109. https://doi.org/10.1097/01.ccm.0000508807.03148.25

[6] Follis, F.M., Pett, S.B. Jr, Miller, K.B., Wong, R.S., Temes, R.T. and Wernly, J.A. (1999) Catastrophic Hemorrhage on Sternal Reentry: Still a Dreaded Complication? The Annals of Thoracic Surgery, 68, 2215-2219. https://doi.org/10.1016/S0003-4975(99)01173-X

[7] Özker, E., Saritas, B., Vuran, C., Yörüker, U., Ulugöl, H. and Türköz, R. (2012) Delayed Sternal Closure after Pediatric Cardiac Operations; Single Center Experience: A Retrospective Study. Journal of Cardiothoracic Surgery, 7, 102. https://doi.org/10.1186/1749-8090-7-102 
[8] Kirshbom, P.M., Myung, R,J., Simsic, J.M., Kramer, K.B., Leong, T., Kogon, B.E. and Kanter, K.R. (2009) One Thousand Repeat Sternotomies for Congenital Cardiac Surgery: Risk Factors for Reentry Injury. The Annals of Thoracic Surgery, 88, 158-161. https://doi.org/10.1016/j.athoracsur.2009.03.082

[9] Jacobs, M.L., O’Brien, S.M., Jacobs, J.P., Mavroudis, C., Lacour-Gayet, F., Pasquali, S.K., Welke, K., Pizarro, C., Tsai, F. and Clarke, D.R. (2013) An Empirically Based Tool for Analyzing Morbidity Associated with Operations for Congenital Heart Disease. The Journal of Thoracic and Cardiovascular Surgery, 145, 1046-1057. https://doi.org/10.1016/j.jtcvs.2012.06.029

[10] Davidson, J., Tong, S., Hancock, H., Hauck, A., da Cruz, E. and Kaufman, J. (2012) Prospective Validation of the Vasoactive-Inotropic Score and Correlation to Short Term Outcomes in Neonates and Infants After Cardiothoracic Surgery. Intensive Care Medicine, 38, 1184-1190. https://doi.org/10.1007/s00134-012-2544-X

[11] Kumar, M., Sharma, R., Sethi, S.K., Bazaz, S., Sharma, P., Bhan, A, and Kher, V. (2014) Vasoactive Inotrope Score as a Tool for Clinical Care in Children Post Cardiac Surgery. Indian Journal of Critical Care Medicine, 18, 653-658. https://doi.org/10.4103/0972-5229.142174

[12] Wernovsky, G., Wypij, D., Jonas, R.A., Mayer, J.E. Jr, Hanley, F.L., Hickey, P.R., Walsh, A.Z., Chang, A.C, Castañeda, A.R., Newburger, J.W. and Wessel, D.L. (1995) Postoperative Course and Hemodynamic Profile after the Arterial Switch Operation in Neonates and Infants. Circulation, 92, 2226-2235.

https://doi.org/10.1161/01.CIR.92.8.2226

[13] Garcia, R.U., Walters, H.L., Delius, R.E. and Aggarwal, S. (2016) Vasoactive Inotropic Score (VIS) as Biomarker of Short-Term Outcomes in Adolescents after Cardiothoracic Surgery. Pediatric Cardiology, 37, 271-277. https://doi.org/10.1007/s00246-015-1273-7

[14] Haque, A., Siddiqui, N.R., Munir, O., Saleem, S. and Mian, A. (2015) Association between Vasoactive-Inotropic Score and Mortality in Pediatric Septic Shock. Indian Pediatrics, 52, 311-313. https://doi.org/10.1007/s13312-015-0630-1

[15] Williams, F.Z., Sachdeva, R., Travers, C.D., Walson, K.H. and Hebbar, K.B. (2016) Characterization of Myocardial Dysfunction in Fluid- and Catecholamine-Refractory Pediatric Septic Shock and its Clinical Significance. Journal of Intensive Care Medicine, 2016, Article ID: 885066616685247.

[16] Bangalore, H., Gaies, M., Ocampo, E.C., Heinle, J.S., Guffey, D., Minard C.G., Checchia, P. and Shekerdemian, L.S. (2017) The Total Inotrope Exposure Score: An Extension of the Vasoactive Inotrope Score as a Predictor of Adverse Outcomes After Paediatric Cardiac Surgery. Cardiology in the Young, 27, 1146-1152. https://doi.org/10.1017/S1047951116002602

[17] Akhtar, M.I., Hamid, M., Minai, F., Wali, A.R., Answar-UI-Haq, Aman-Ullah, M. and Ahsan, K. (2014) Safety Profile of Fast-Track Extubation in Pediatric Congenital Heart Disease Surgery Patients in a Tertiary Care Hospital of Developing Country: An Observational Prospective Study. Journal of Anaesthesiology Clinical Pharmacology, 30, 355-359. https://doi.org/10.4103/0970-9185.137267

[18] Harris, K.C., Holowachuk, S., Pitfield, S., Sanatani, S., Froese, N., Potts, J.E. and Gandhi, S.K. (2014) Should Early Extubation Be the Goal for Children after Congenital Cardiac Surgery? The Journal of Thoracic and Cardiovascular Surgery, 148, 2644-2647. https://doi.org/10.1016/j.jtcvs.2014.06.093

[19] Ödek, C., Kendirli, T., Ucar, T., Yaman, A., Tutar, E., Eyileten, Z., Tasar, M., Ramoğlu, M, Ates, C., Uysalel, A., Ince, E. and Atalay, S. (2016) Predictors of Early Extubation after Pediatric Cardiac Surgery: A Single-Center Prospective Observa- 
tional Study. Pediatric Cardiology, 37, 1241-1249. https://doi.org/10.1007/s00246-016-1423-6

[20] Marwali, E.M., Budiwardhana, N., Sastroasmoro, S., Pudjiadi, A. and Haas, N.K. (2013) Prediction Model for Length of Intubation with Assisted Mechanical Ventilation in Pediatric Heart Surgery. Critical Care \& Shock, 16, 74-82.

[21] Polito, A., Patorno, E., Costello, J.M., Salvin, J.W., Emani, S.M., Rajagopal, S., Laussen, P.C. and Thiagarajan, R.R. (2011) Perioperative Factors Associated with Prolonged Mechanical Ventilation after Complex Congenital Heart Surgery. Pediatric Critical Care Medicine, 12, e122-e126.

https://doi.org/10.1097/PCC.0b013e3181e912bd

[22] Székely, A., Sápi, E., Király, L., Szatmári, A. and Dinya, E. (2006) Intraoperative and Postoperative Risk Factors for Prolonged Mechanical Ventilation after Pediatric Cardiac Surgery. Pediatric Anesthesia, 16, 1166-1175. https://doi.org/10.1111/j.1460-9592.2006.01957.x

[23] Tabib, A., Abrishami, S.E., Mahdavi, M., Mortezaeian, H. and Totonchi, Z. (2016) Predictors of Prolonged Mechanical Ventilation in Pediatric Patients after Cardiac Surgery for Congenital Heart Disease. Research in Cardiovascular Medicine, 5, 330-391. https://doi.org/10.5812/cardiovascmed.30391

[24] Baker-Smith, C.M., Wilhelm, C.M., Neish, S.R., Klitzner, T.S., Beekman, R.H., Kugler, J.D., Martin, G.R., Lannon, C., Jenkins, K.J. and Rosenthal, G.L. (2014) Predictors of Prolonged Length of Intensive Care Unit Stay after Stage I Palliation: A Report from the National Pediatric Cardiology Quality Improvement Collaborative. Pediatric Cardiology, 34, 431-440. https://doi.org/10.1007/s00246-013-0797-y

[25] Izenman, A.J. (2013) Recursive Partitioning and Tree-Based Methods. In: Izenman, A.J., Ed., Modern Multivariate Statistical Techniques, Regression, Classification and Manifold Learning, Springer Texts in Statistics, Springer, Berlin, 271-314. https://doi.org/10.1007/978-0-387-78189-1_9

[26] Zhang, H. and Singer, B. (2010) Recursive Partitioning and Applications. In: Zhang, H. and Singer, B., Eds., Recursive Partitioning and Applications, 2nd Edition, Springer, Berlin, Chapters 1-4, 6, 8, 9. https://doi.org/10.1007/978-1-4419-6824-1 